(C) 2021, The Authors. Published by Elsevier Inc. and Fass Inc. on behalf of the American Dairy Science Association ${ }^{\circledR}$. This is an open access article under the CC BY-NC-ND license (http://creativecommons.org/licenses/by-nc-nd/4.0/).

\title{
Short communication: Efficacy of a second intrauterine cephapirin infusion for the treatment of purulent vaginal discharge and endometritis in postpartum dairy cows
}

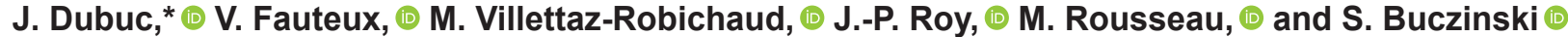 \\ Faculté de médecine vétérinaire, Université de Montréal, 3200 rue Sicotte, Saint-Hyacinthe, Québec, J2S 2M2, Canada
}

\section{ABSTRACT}

The objective of this study was to quantify the efficacy of a second intrauterine cephapirin treatment administered $14 \mathrm{~d}$ after the initial one on subsequent reproductive performance of postpartum dairy cows affected by purulent vaginal discharge (PVD) or endometritis (ENDO). In total, 4,140 Holstein cows from 30 commercial herds were enrolled in a randomized clinical trial. At $36( \pm 7) \mathrm{d}$ in milk, cows were examined using the Metricheck device to diagnose PVD. An endometrial cytology sample was also collected from each cow to perform a leukocyte esterase test for diagnosing ENDO. Diagnosis of PVD and ENDO was done cow-side. Cows diagnosed with PVD or ENDO were assigned to receive 1 of 2 treatments: (1) a single intrauterine cephapirin infusion (500 $\mathrm{mg}$ of cephapirin benzathin; Metricure, Merck Animal Health, Kirkland, QC, Canada) at the time of initial examination or (2) a single intrauterine infusion at the time of initial examination and a second one $14 \mathrm{~d}$ later. Subsequent reproductive and culling events were collected until 200 $\mathrm{d}$ in milk. Statistical analyses were performed using univariable and multivariable mixed logistic regression models. In cows affected by PVD, a second intrauterine cephapirin infusion increased the pregnancy risk at first insemination in comparison with cows that only received one treatment ( 28.0 vs. $38.8 \%$ ). In cows affected by ENDO, a second treatment also increased the pregnancy risk at first insemination compared with cows that only received one treatment (30.3 vs. $39.2 \%$ ). Overall, these results demonstrate that administering a second intrauterine cephapirin infusion $14 \mathrm{~d}$ after the initial treatment in postpartum cows affected by PVD or ENDO did improve their subsequent reproductive performance.

Key words: dairy cow, cephapirin, purulent vaginal discharge, endometritis

Received August 27, 2020.

Accepted October 15, 2020

*Corresponding author: Jocelyn.dubuc@umontreal.ca

\section{Short Communication}

Purulent vaginal discharge (PVD) and endometritis (ENDO) are common postpartum reproductive tract diseases in dairy cows (Cheong et al., 2011; Dubuc and Denis-Robichaud, 2017) and have a negative effect on subsequent reproductive performance (LeBlanc et al., 2002a; Dubuc et al., 2010; de Boer et al., 2015). Multiple studies have shown the efficacy of intrauterine cephapirin (CEPHA) administration for treating PVD and ENDO (LeBlanc et al., 2002b; Kasimanickam et al., 2005; Denis-Robichaud and Dubuc, 2015b). In these studies, a single infusion of CEPHA improved the subsequent reproductive performance of treated cows compared with untreated ones. Over the last $20 \mathrm{yr}$, the availability of cow-side tests for diagnosing PVD and ENDO has increased the awareness about these diseases on dairy farms. Interestingly, veterinarians and dairy producers frequently using CEPHA infusion are questioning if there is a benefit on reproductive performance when administering a second CEPHA treatment during the weeks following the initial one. Unfortunately, no data are currently available to answer this question.

Therefore, the objective of this study was to quantify the efficacy of a second CEPHA treatment, administered $14 \mathrm{~d}$ after the initial one, on subsequent reproductive performance of postpartum dairy cows affected by PVD or ENDO. Our hypothesis was that cows receiving 2 CEPHA treatments would have improved reproductive performance compared with cows that only received one treatment.

Cows from 30 commercial Holstein dairy herds were enrolled in a randomized clinical trial approved by the Animal Care Committee of the Université de Montréal (20-Rech-2061). Herd selection was based on convenience for being located within $1 \mathrm{~h}$ of St-Hyacinthe (QC, Canada), for being a client of the bovine ambulatory clinic of the Faculté de médecine vétérinaire of the Université de Montréal (St-Hyacinthe, QC, Canada), for having a history of elevated PVD or ENDO prevalence, for being visited by a veterinarian every $2 \mathrm{wk}$ 
(herd health medicine program), and for using a systematic ovulation synchronization protocol for the first insemination of cows during their lactation (around 70 DIM).

Once participation was agreed upon, herds were visited every $14 \mathrm{~d}$ by an animal health technician. During farm visits, cows were enrolled at $36( \pm 7)$ DIM and were examined for reproductive tract diseases. Cows having a "do not breed" status were not enrolled. After identifying the cows, the vulva was cleaned with paper towels and water, and a Metricheck device (Simcro, Hamilton, New Zealand) was used to assess vaginal discharge. Scoring was defined as $0=$ no discharge, $1=$ clear mucus, $2=$ mucus with flecks of pus, $3=$ mucopurulent discharge, $4=$ purulent discharge, and $5=$ foul-smelling discharge (McDougall et al., 2007). Diagnosis of PVD was based on having a vaginal score $\geq 3$. Once Metricheck testing was completed, a cytological sample from the endometrium located in the body of the uterus was collected using the cytobrush technique (Kasimanickam et al., 2004). Once the cytobrush was retrieved from the uterus, a leukocyte esterase test was performed. The cytobrush was immerged into a vial containing $1 \mathrm{~mL}$ of physiological saline $(\mathrm{NaCl}$ $0.9 \%$ Irrigation, Baxter Corporation, Mississauga, ON, Canada), and a leukocyte esterase strip (Multistix 10 SG, Bayer Corporation, Elkart, IN) was dipped in the solution (Denis-Robichaud and Dubuc, 2015a). Scoring was done after a waiting period of 2 min and was defined as $0=$ negative, $0.5=$ trace of leukocytes, $1=$ small amount of leukocytes, $2=$ moderate amount of leukocytes, and $3=$ large amount of leukocytes (Couto et al., 2013). Diagnosis of ENDO was based on having a leukocyte esterase test score $\geq 1$ (Denis-Robichaud and Dubuc, 2015a). Diagnosis of PVD and ENDO were both done cow-side.

All cows that were not affected by PVD or ENDO at $36( \pm 7)$ DIM were enrolled in the unaffected group. Within each participating herd, all cows diagnosed with PVD or ENDO were randomly allocated (coin toss) to 1 of 2 treatment groups. Cows in the first group (CEPH1X) received a single CEPHA intrauterine infusion (500 $\mathrm{mg}$ of cephapirin benzathin; Metricure, Merck Animal Health, Kirkland, QC, Canada) at the time of initial examination. Cows in the second group (CEPH2X) received a single CEPHA intrauterine infusion (500 $\mathrm{mg}$ of cephapirin benzathin; Metricure, Merck Animal Health, Kirkland, QC, Canada) at the time of initial examination and a second one $(500 \mathrm{mg}$ of cephapirin benzathin; Metricure, Merck Animal Health, Kirkland, QC, Canada) 14 d later (50 \pm 7 DIM). Farmers were blinded to disease diagnosis and treatment allocation, whereas the research staff were not.
Treatment group allocation was stratified based on reproductive tract disease status (PVD-CEPH1X vs. PVD-CEPH2X; ENDO-CEPH1X vs. ENDOCEPH2X). Cows simultaneously having PVD and ENDO were enrolled in both strata and allocated to the same treatment group (CEPH1X or CEPH2X) by performing only one coin toss. In the end, there were 5 treatment groups of cows in this experiment (unaffected, PVD-CEPH1X, PVD-CEPH2X, ENDOCEPH1X, and ENDO-CEPH2X). A sample size of 350 cows per treatment group was estimated for the study based on finding a difference of $10 \%$ in pregnancy risk at first insemination (PRFI) between treatment groups (CEPH1X: 30\%; CEPH2X: 40\%), with 95\% confidence and $80 \%$ power (Dohoo et al., 2003). Therefore, 700 cows with PVD and 700 cows with ENDO needed to be recruited. Based on an estimated PVD prevalence of $17 \%$, a total of 4,200 cows would have been necessary. Based on an estimated ENDO prevalence of $20 \%$, a total of 3,500 cows would have been necessary. In the end, a total of 4,200 cows was targeted for this study as the most limiting sample size.

In all herds, timed AI was exclusively used for breeding. The voluntary waiting period in these herds was 50 DIM. Pregnancy diagnosis was performed by transrectal palpation (using ultrasonography when needed) between 32 and $46 \mathrm{~d}$ after insemination. Reproductive and culling events were monitored until 200 DIM.

All statistical analyses were performed using SAS version 9.4 (SAS Institute Inc., Cary, NC). The unit of interest in this study was the cow. Individual cow data such as parity (first, second, third, or greater), season of calving (winter: January to March; spring: April to June; summer: July to September; fall: October to December), as well as reproductive and culling events were collected. Descriptive statistics were computed using the FREQ procedure. Prevalence of parity group, season of calving, PVD, ENDO, culling, and PRFI were computed overall and within each stratified subgroup (unaffected, PVD-CEPH1X, PVD-CEPH2X, ENDO-CEPH1X, and ENDO-CEPH2X). Univariable associations between PRFI and each aforementioned variable were computed using mixed logistic regression models accounting for herd clustering (random intercept; PROC GLIMMIX). A multivariable mixed logistic regression model accounting for herd clustering as a random effect (PROC GLIMMIX) was built. This model considered PRFI as the dependent variable and treatment and disease strata as the main independent variables. Parity and season of calving were offered to the model as confounders and were kept if their effect was greater than 10\% (Maldonado and Greenland, 1993). Least squares means were computed from the fi- 
nal model, and differences between least squares means were calculated using a Tukey-Kramer test.

A total of 4,248 Holstein cows from 30 herds were enrolled in this study. Most participating herds $(\mathrm{n}=21)$ were housed in tiestall facilities (9 herds were housed in freestall facilities). Of all the cows initially enrolled, 108 cows were excluded because they were not bred by 100 DIM (do not breed status) or they were culled before pregnancy diagnosis after the first insemination. Therefore, 4,140 cows were used for data analysis. The median herd size was 86 cows (minimum: 58, maximum: 421). Overall, the prevalence of PVD and ENDO at first examination $(36 \pm 7$ DIM $)$ was $25.1 \%(\mathrm{n}=1,038)$ and $37.6 \%(\mathrm{n}=1,557)$, respectively. The median herd prevalence of PVD was $24.3 \%$ (minimum: $13.4 \%$, maximum: $52.9 \%$ ) and $38.5 \%$ for ENDO (minimum: $14.5 \%$, maximum: $68.7 \%$ ). The prevalence of the unaffected group was $47.0 \%$ ( $\mathrm{n}=1,946)$, and 401 cows simultaneously had PVD and ENDO. Of all the cows with PVD at first examination $(\mathrm{n}=1,038), 522(50.3 \%)$ and 516 (49.7\%) cows were allocated to CEPH1X and CEPH2X treatment groups, respectively. Of all the cows with ENDO at first examination $(\mathrm{n}=1,557), 772(49.6 \%)$ and $785(50.4 \%)$ cows were allocated to the CEPH1X and CEPH2X treatment groups, respectively. Descriptive statistics of the studied population are presented in Table 1.

In univariable models, parity group, season of calving, treatment group, and disease status were associated with PRFI $(P<0.05)$. In the multivariable model, parity group, season of calving, treatment group, and disease status were associated with PRFI $(P<$ 0.05). Least squares means from the final model are presented in Figure 1. This figure shows that CEPHA treatment increased PRFI in cows affected by PVD at first examination (CEPH1X: 28.0\%; CEPH2X: 38.8\%; $P=0.01)$. A similar effect of CEPHA treatment was noted in cows affected by ENDO at first examination (CEPH1X: 30.3\%; CEPH2X: 39.2\%; $P=0.03$ ). Cows in the unaffected group had a PRFI of $43.2 \%$.

This study is the first one to report a benefit of administering a second CEPHA infusion treatment in postpartum cows affected by PVD and ENDO. Based on our results, the magnitude of this benefit for PVD was an increase of 10 percentage points in PRFI in comparison with cows only given one CEPHA infusion. For ENDO, it was an increase of 9 percentage points. When interpreting these data, it is important to keep in mind that all cows had their first insemination performed following a systematic ovulation synchronization protocol. This approach was chosen as a way to control for the stage of lactation at which first inseminations occurred. It is unclear if similar results would have been found when using estrus detection for first insemination.

Because of the study design, the benefit of a second treatment can only be compared with cows receiving one CEPHA treatment (positive control group) or to cows unaffected by any reproductive tract diseases. It was not the objective of the present study to quantify the effect of administering one CEPHA treatment (i.e., compared with no treatment at all); such studies have been performed in the past (LeBlanc et al., 2002b; Runciman et al., 2009; Denis-Robichaud and Dubuc, 2015b). The sample size needed for each additional treatment group in our study was 350 cows affected by PVD; the same number applied for ENDO. Unfortunately, it was not logistically feasible to include additional treatment groups in the present study as the study size was already large enough. Future studies on this topic should therefore consider a study design that allows such investigation, if feasible. Future studies should also consider including bacteriological culture in their investigation to properly diagnose the presence of uterine pathogens and possibly allow specific

Table 1. Descriptive statistics from a randomized clinical trial investigating the efficacy of a second intrauterine cephapirin treatment (in comparison with only one treatment) in 4,140 postpartum dairy cows

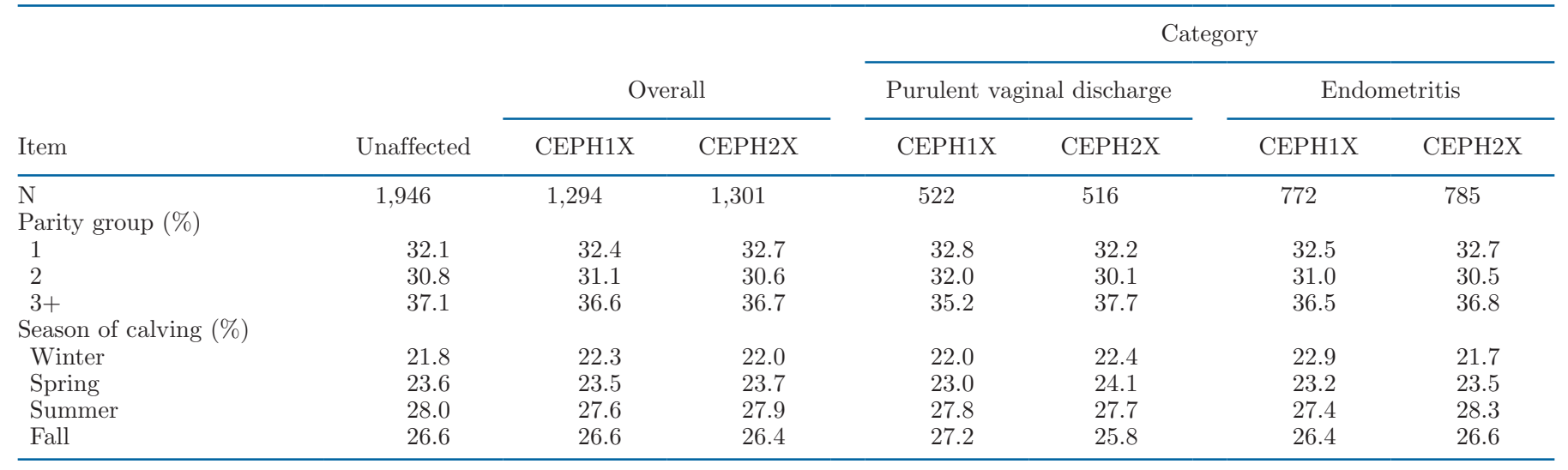


identification. Unfortunately, the current study did not include bacteriological testing, which led to the use of cephalosporin in cows without identification of pathogens. Considering the current worldwide pressure about prudent antibiotic drug use, this strategy might need to be revisited and refined in the future.

Although diagnosing ENDO with the leukocyte esterase test is convenient and can be done cow-side, one should keep in mind that the results of the present study might not have been exactly the same if using the endometrial cytology test (i.e., microscope slide reading). Leukocyte esterase and endometrial cytology are both well accepted diagnostic tests for ENDO and their results are associated with detrimental effects on the subsequent reproductive performance of cows (Couto et al., 2013; Denis-Robichaud and Dubuc, 2015a). It remains unclear if conducting the present study with endometrial cytology instead of the leukocyte esterase test would have provided different results. Further research should clarify this point.

It was not logistically and financially possible to diagnose prolonged anovulation in cows during the present study. It has been shown that prolonged anovulation and postpartum reproductive tract diseases are associated (Krause et al., 2014; Vieira-Neto et al., 2014). Another study also suggested that the effect of intrauterine CEPHA treatment on PRFI is modulated by the anovulation status of cows, the magnitude of the effect being greater in ovular cows than in anovular cows (Denis-Robichaud and Dubuc, 2015b). It is highly possible that the benefit of a second CEPHA treatment is also modulated by prolonged anovulation. Unfortunately, this relationship cannot be explored in our data. This aspect should be explored in future studies.

In conclusion, the administration of a second intrauterine CEPHA infusion $14 \mathrm{~d}$ after the initial treatment improved the subsequent reproductive performance of postpartum cows affected by PVD or ENDO. In the context of our study, the benefit of a second treatment was an increase of 10 and 9 percentage points in PRFI of cows affected by PVD and ENDO, respectively.

\section{ACKNOWLEDGMENTS}

This project was financially supported by Merck Animal Health (Kirkland, QC, Canada), "Fonds de Recherche du Québec-Nature et Technologies" (Québec, QC, Canada), and "Réseau Québécois en Reproduction" (Université de Montréal, St-Hyacinthe, QC, Canada). The authors acknowledge the technical work provided by Jean-Philippe Pelletier (St-Hyacinthe, QC, Canada) and the participating dairy producers for their contribution to this study. The authors also express gratitude to Guy Boisclair (Victoriaville, QC, Canada)

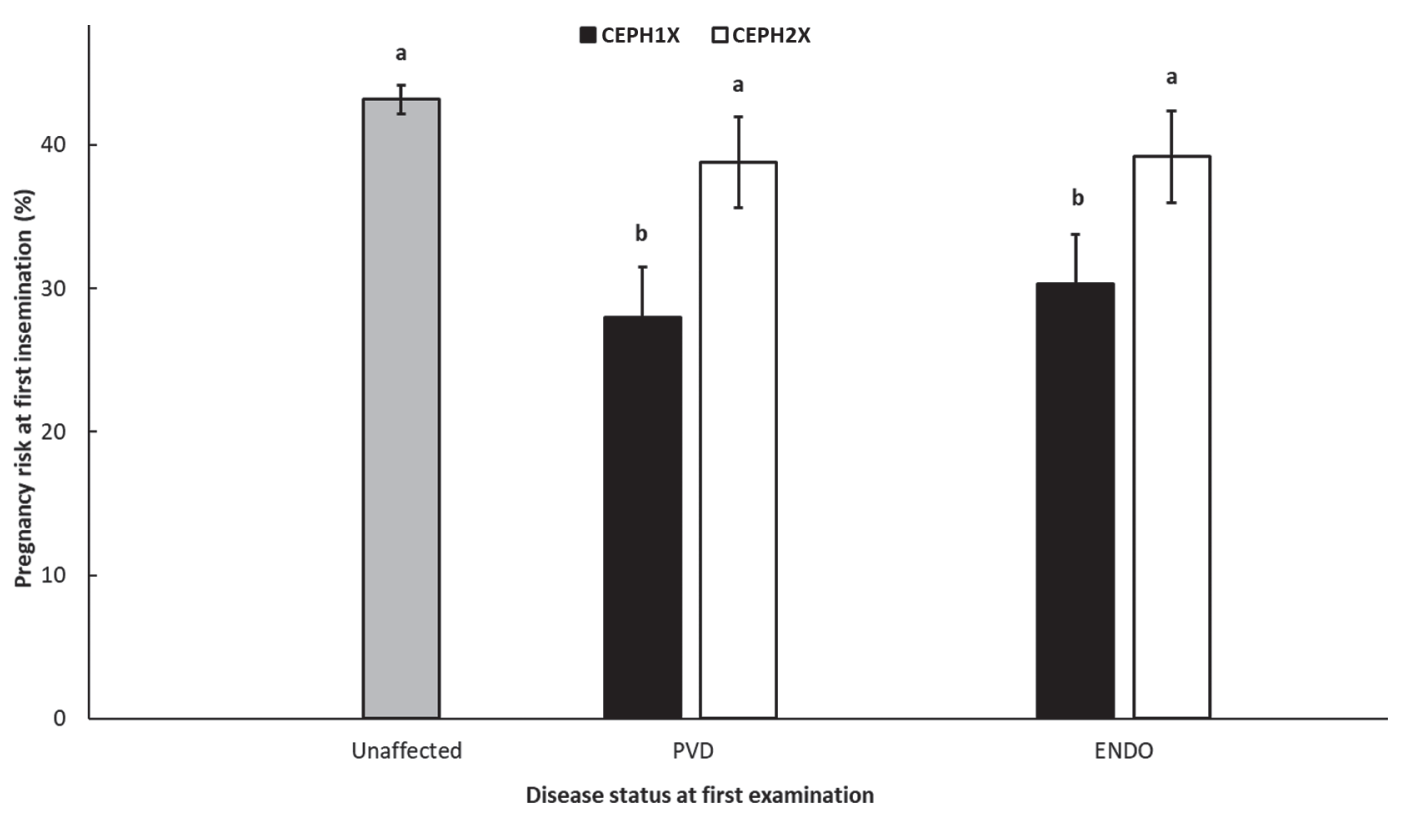

Figure 1. Least squares means $( \pm \mathrm{SEM})$ of intrauterine cephapirin treatment groups at $36( \pm 7)$ DIM on pregnancy risk at first insemination stratified by reproductive tract disease status (unaffected; purulent vaginal discharge: PVD; endometritis: ENDO) in 4,140 Holstein cows enrolled in a randomized clinical trial. Different lowercase letters $(\mathrm{a}, \mathrm{b})$ indicate a significant difference $(P<0.05)$. CEPH1X refers to a single treatment of intrauterine cephapirin at $36( \pm 7)$ DIM. CEPH2X refers to a treatment of intrauterine cephapirin at $36( \pm 7)$ DIM and a second one at $50( \pm 7)$ DIM. 
and Jantijn Swinkels (Boxmeer, the Netherlands) for their great interest in this study. The authors have not stated any conflicts of interest.

\section{REFERENCES}

Cheong, S. H., D. V. Nydam, K. N. Galvão, B. M. Crosier, and R. O. Gilbert. 2011. Cow-level and herd-level risk factors for subclinical endometritis in lactating Holstein cows. J. Dairy Sci. 94:762-770. https://doi.org/10.3168/jds.2010-3439.

Couto, G. B., D. H. Vaillancourt, and R. C. Lefebvre. 2013. Comparison of a leukocyte esterase test with endometrial cytology for diagnosis of subclinical endometritis in postpartum dairy cows. Theriogenology 79:103-107. https://doi.org/10.1016/j.theriogenology .2012.09.014

de Boer, M., B. M. Buddle, C. Heuer, H. Hussein, T. Zheng, S. J. LeBlanc, and S. McDougall. 2015. Associations between intrauterine bacterial infection, reproductive tract inflammation, and reproductive performance in pasture-based dairy cows. Theriogenology 83:1514-1524. https://doi.org/10.1016/j.theriogenology.2015.01 .032 .

Denis-Robichaud, J., and J. Dubuc. 2015a. Determination of optimal diagnostic criteria for purulent vaginal discharge and cytological endometritis in dairy cows. J. Dairy Sci. 98:6848-6855. https://doi .org/10.3168/jds.2014-9120.

Denis-Robichaud, J., and J. Dubuc. 2015b. Randomized clinical trial of intrauterine cephapirin infusion in dairy cows for the treatment of purulent vaginal discharge and cytological endometritis. J. Dairy Sci. 98:6856-6864. https://doi.org/10.3168/jds.2014-9129.

Dohoo, I., W. Martin, and H. Stryhn. 2003. Veterinary Epidemiologic Research. 1st ed. AVC Inc., Charlottetown, PE, Canada.

Dubuc, J., and J. Denis-Robichaud. 2017. A dairy herd-level study of postpartum diseases and their association with reproductive performance and culling. J. Dairy Sci. 100:3068-3078. https://doi .org/10.3168/jds.2016-12144.

Dubuc, J., T. F. Duffield, K. E. Leslie, J. S. Walton, and S. J. LeBlanc. 2010. Definitions and diagnosis of postpartum endometritis in dairy cows. J. Dairy Sci. 93:5225-5233. https://doi.org/10 3168/jds.2010-3428.

Kasimanickam, R., T. F. Duffield, R. A. Foster, C. J. Gartley, K. E. Leslie, J. S. Walton, and W. H. Johnson. 2004. Endometrial cytology and ultrasonography for the detection of subclinical endometritis in postpartum dairy cows. Theriogenology 62:9-23. https:// doi.org/10.1016/j.theriogenology.2003.03.001.

Kasimanickam, R., T. F. Duffield, R. A. Foster, C. J. Gartley, K. E. Leslie, J. S. Walton, and W. H. Johnson. 2005. The effect of a single administration of cephapirin or cloprostenol on the reproductive performance of dairy cows with subclinical endometritis. The- riogenology 63:818-830. https://doi.org/10.1016/j.theriogenology 2004.05.002.

Krause, A. R. T., L. F. M. Pfeifer, P. Montagner, M. M. Weschenfelder, E. Schwegler, M. E. Lima, E. G. Xavier, C. C. Brauner, E. Schmitt, F. A. B. Del Pino, C. F. Martins, M. N. Corrêa, and A. Schneider. 2014. Associations between resumption of postpartum ovarian activity, uterine health and concentrations of metabolites and acute phase proteins during the transition period in Holstein cows. Anim. Reprod. Sci. 145:8-14. https://doi.org/10.1016/j .anireprosci.2013.12.016.

LeBlanc, S. J., T. F. Duffield, K. E. Leslie, K. G. Bateman, G. P. Keefe, J. S. Walton, and W. H. Johnson. 2002a. Defining and diagnosing postpartum clinical endometritis and its impact on reproductive performance in dairy cows. J. Dairy Sci. 85:2223-2236. https://doi.org/10.3168/jds.S0022-0302(02)74302-6.

LeBlanc, S. J., T. F. Duffield, K. E. Leslie, K. G. Bateman, G. P. Keefe, J. S. Walton, and W. H. Johnson. 2002b. The effect of treatment of clinical endometritis on reproductive performance in dairy cows. J. Dairy Sci. 85:2237-2249. https://doi.org/10.3168/ jds.S0022-0302(02)74303-8.

Maldonado, G., and S. Greenland. 1993. Simulation study of confounder-selection strategies. Am. J. Epidemiol. 138:923-936. https: //doi.org/10.1093/oxfordjournals.aje.a116813.

McDougall, S., R. Macaulay, and C. Compton. 2007. Association between endometritis diagnosis using a novel intravaginal device and reproductive performance in dairy cattle. Anim. Reprod. Sci. 99:923. https://doi.org/10.1016/j.anireprosci.2006.03.017.

Runciman, D. J., G. A. Anderson, and J. Malmo. 2009. Comparison of two methods of detecting purulent vaginal discharge in postpartum dairy cows and effect of intrauterine cephapirin on reproductive performance. Aust. Vet. J. 87:369-378. https://doi.org/10 $.1111 / \mathrm{j} .1751-0813.2009 .00469 . x$

Vieira-Neto, A., R. O. Gilbert, W. R. Butler, J. E. P. Santos, E. S. Ribeiro, M. M. Vercouteren, R. G. Bruno, J. H. J. Bittar, and K. N. Galvão. 2014. Individual and combined effects of anovulation and cytological endometritis on the reproductive performance of dairy cows. J. Dairy Sci. 97:5415-5425. https://doi.org/10.3168/ jds.2013-7725.

\section{ORCIDS}

J. Dubuc ๑ https://orcid.org/0000-0003-1013-8372

V. Fauteux (ㄴ) https://orcid.org/0000-0002-8786-2038

M. Villettaz-Robichaud @ https://orcid.org/0000-0001-9685-1827

J.-P. Roy @ https://orcid.org/0000-0002-0444-2303

M. Rousseau $\odot$ https://orcid.org/0000-0002-2702-434X

S. Buczinski ๑ https://orcid.org/0000-0002-8460-4885 